\title{
Online Test Paper Composition Based on Genetic Algorithm
}

\author{
Wanli Song, ${ }^{1,2} *$ \\ ${ }^{1}$ School of Information Engineering, Nanjing Xiaozhuang University, Nanjing, 211171, China \\ ${ }^{2}$ Key Laboratory of Trusted Cloud Computing and Big Data Analysis, Nanjing XiaoZhuang University, Nanjing, China \\ ${ }^{*}$ Corresponding author
}

\begin{abstract}
The application of online examination is used more and more widely. Test paper composition is the core function in this application. Online examination system requires that the test paper should be quick and flexible, and the composition of questions should be reasonable and random. Test paper should not only meet the specific needs of users, ensure fairness, impartiality, but also be accurate and efficient. The intelligent test paper composition algorithm based on genetic algorithm is studied in this paper. Then this method is used to organize the structure of the test paper automatically, composites the examination content. Proposals are put forward to examines the degree of students' mastery of knowledge based on this method. This algorithm can automatically composite test papers according to the conditions of difficulty degree, knowledge coverage, and the proportion of questions. It can automatically composite test papers for online assessment. The practice of online testing system based on this algorithm shows that the algorithm is scientific and effective. On the premise of guaranteeing the quality of the test paper, it greatly improves the efficiency and pertinence of online testing. It is beneficial to improve students' learning efficiency and intellectualization of education.
\end{abstract}

Keywords-test paper composition; education intellectualization; genetic algorithm; E-learning

\section{INTRODUCTION}

Examination plays an irreplaceable role in any educational system, because it can objectively evaluate the grasping of the knowledge and skills learned by the students. Through the analysis of the results, reference information is provided to measure the teaching situation and teaching effect of teachers to a certain extent. At the same time, for teachers it can also improve teaching methods and teaching quality. [1] Some of our familiar examination systems, such as various academic examination, grade certificate examination, qualification certificate examination, are all due to the popularization of computer technology, and the education industry develops its own test management software independently. The emergence of these intelligent examination system solves many problems which are easy to appear in the traditional examination. It saves the manpower and financial resources. It also realizes the fairness, objectivity and accuracy of the examination while improving the efficiency of the teacher's work. The practice of integrating modern technology into the education industry is a good example of "promoting teaching and learning through examinations". [2]
With the rapid development of related technologies and the environmental protection and conservation proposed by the state, examinations also require fairness and paperless development. This requires the development of the examination system to be intelligent, and the score should be more reasonable and scientific. The rapid development of artificial intelligence technology can achieve this demand better. In recent years, the domestic research work on intelligent test paper has also developed greatly. The main content of the study is to analyze and improve the existing excellent algorithms, and to establish mathematical models through the analysis of these algorithms. [3] The whole process of examination, including marking process, is realized on the Internet. To ensure that the whole examination system has a scientific guarantee, it is necessary to make it scientific and reasonable. Through the investigation and research, it is found that some of the existing test paper algorithms are relatively simple, and the function of the intelligent test paper is not very strong, and at some time it cannot be very good to meet the higher needs of the teachers. In general, when the examination system is not very large, the test paper can satisfy the constraint condition according to certain algorithm. However, when there are more extensive subjects and more examination questions, the system may enter an infinite loop, resulting in the paralysis of the running system. The test paper could not be extracted successfully. There are also some better algorithms. Indeed, in some cases, these algorithms can satisfy our requirements, such as backtracking algorithm. But the time complexity of the algorithm is increasing, so that it cannot achieve the best result in the end.

In this study, we design an online test paper composition algorithm and test system for the course knowledge of data structure. After students enter the online learning platform, the system will give a suitable test question according to their learning situation during the study of the course of data structure. According to the students' selection of the constraints such as curriculums, chapters, knowledge points, difficulties and distinctions, the system can use the algorithms to form a test paper to meet the needs of the students and use it for the students' online testing. This series of study can promote the development of teaching in the direction of intelligence. [5]

\section{APPROACH}

In this section we present an approach for constructing online test paper composition system. 


\section{A. Using the Fitness Calculation to Obtain the Desired Test Questions}

In biology, the survival of the fittest is eliminated, and there is a similar principle in the test paper composition. The test questions with high fitness will be retained and low fitness will be eliminated. In this design, the fitness calculation formula (1) is selected to achieve the goal of solving the problem, where $c_{i}$ is the paper unit knowledge point coverage, $\mathrm{d}_{\mathrm{i}}$ is the paper unit difficulty, $\mathrm{w}_{\mathrm{dp}}$ is the weight of knowledge point coverage, $\mathrm{w}_{\mathrm{pd}}$ is the paper difficulty, $w_{d}$ is the weight of paper difficulty, $\mathrm{w}_{\mathrm{pd}}+\mathrm{w}_{\mathrm{d}}=1$.

$$
f_{i}=1-\left(1-c_{i}\right) w_{k p}-\left|d_{i}-w_{p d}\right| w_{d}, i=1,2,3, \ldots, n
$$

Survival of the fittest is a strategy of choice for future generations. The typical choice strategy is roulette selection strategy, which is used in our approach. Roulette is to extract offspring according to a certain probability and repeat $\mathrm{n}$ times iteratively, so that the median probability of each individual is calculated according to formula (2) where $\mathrm{x}_{\mathrm{i}}$ and $\mathrm{x}_{\mathrm{j}}$ is one of the paper unit, $f(x)$ is the function of the remain proportion.

$$
P \mathrm{i}=\frac{f(\mathrm{xi})}{\sum_{j=1}^{n} f(x j)}
$$

\section{B. Using Intersection Calculation to Get a New Test Paper}

Intersecting in biology refers to the exchange of chromosome fragments to produce two new offspring (chromosome recombination), which is simply to randomly select two individuals to cross and produce a new progeny as shown in Figure 1.

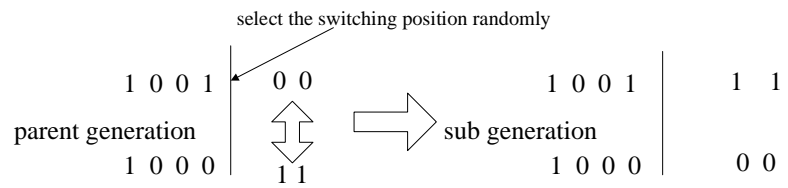

FIGURE I. INTERSECTING A NEW GENERATION OF INDIVIDUALS

The intersection strategy used in our approach is that two integer $\mathrm{N} 1$ is randomly produced between $(0, \mathrm{~N})$, N2, the genes of N1 to N2 in the sequence of father gene are all inherited to the progeny, and the gene from N1 to N2 in the mother gene sequence is inherited to the progeny, but it is necessary to ensure that the gene is not repeated, if repeated (experiments prove that there is a larger probability. In order to ensure that the relative position of the genes on the chromosomes is the same, it is necessary to select one of the questions with the same type, the same score and the same knowledge points included in the question bank.

\section{Using Variation Calculation to Remove Questions not Satisfied}

The so-called mutation is also known as gene mutation in biology. It refers to a gene segment of a chromosome or a gene point mutation, as shown in Figure 2. This is a typical single point mutation diagram. The diversity of the population has been increased officially because of variation, and its role is to get rid of the local best and go to a better place, which is of great randomness. In this system, every gene of every individual has the chance of mutation. If the probability of random is less than the mutation probability, then the gene may mutate. The principle of mutation is: the same question type, the same score and the same point of knowledge with the original problem. The study shows that the selection of mutation probability is best between 0.1-0.001, and the variation probability of the noumenon is $0-1$ due to the limit of the number of subjects. In this example, 0.085 is selected as the mutation probability.

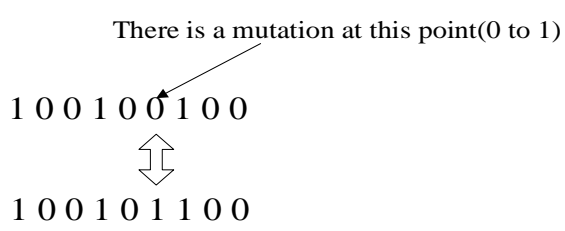

FIGURE II. SINGLE POINT MUTATION

\section{SYSTEM IMPLEMENTATION}

\section{A. Implementation Technologies}

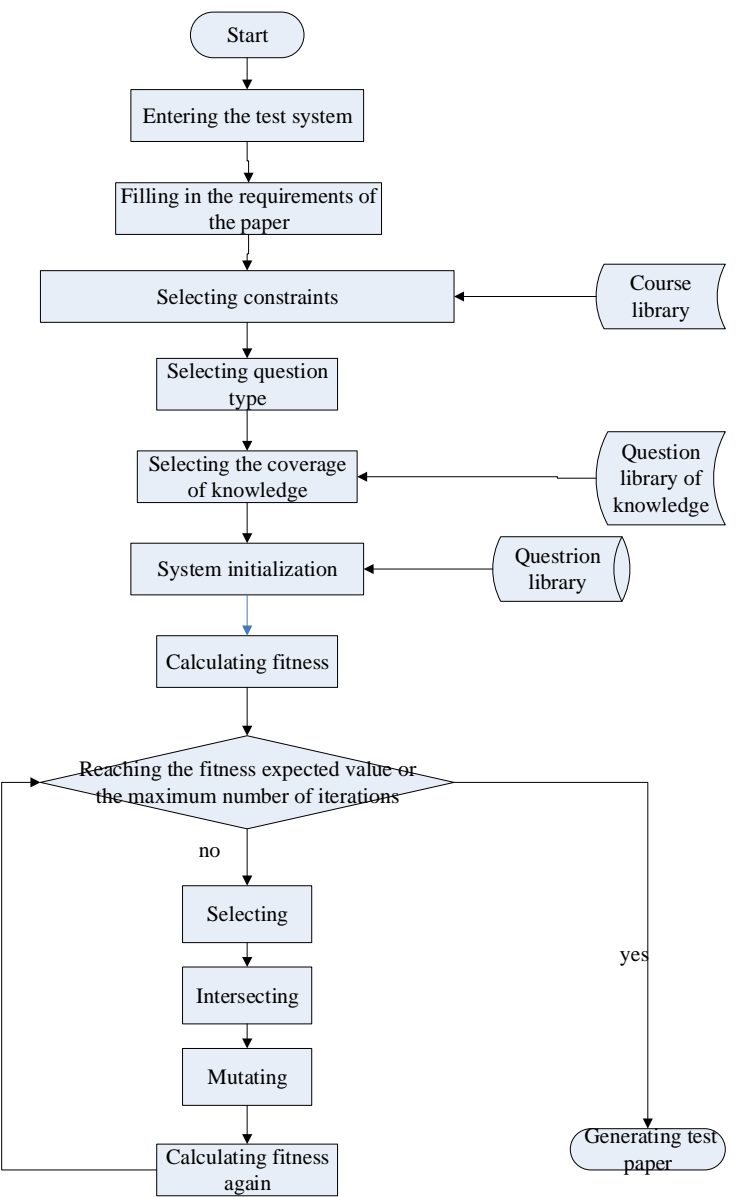

FIGURE III. INTELLIGENT TEST PAPER COMPOSITION FLOW 
The system is developed based on JavaEE6.0 and MySQL. The main process starts from the user entry system, the user first fills in the request of the organization, then selects the course according to the course library, and fills in the request of the test paper for the difficulty and the degree of distinction of the examination paper. Then according to the existing problems of the system to set the test paper to set the user to set the type of questions, and then according to the existing knowledge point library, users choose the scope of knowledge point, and the corresponding selection of knowledge points according to their needs. Through the selection of a series of users' requirements, the system extracts the questions from the question bank and codes the test questions. After the calculation of the algorithms, such as cross, selection and variation, the test questions satisfy the user's expectation. If the expectation is not satisfied, the system will continue to iterate and know the test paper full of user needs. The process flow of the intelligent test paper composition is shown in Figure 3.

\section{B. Experimental Method}

The purpose of this study is to implement online test paper and evaluation based on genetic algorithm, which requires a large number of question library. Therefore, many research and collation are carried out in the early stage of this study. The system uses 5000 topics for the use of the system. First, the relationship between the courses, chapters, sections, and knowledge points. The associated data is stored in the database for the purpose of compositing the test paper function. In the process of organizing the papers, the conditions for the user's desired test papers are specified: the type of questions, the number of questions, the difficulty of the examination questions, the coverage rate of the test questions, the total score of the papers and so on. In this study, the independent test of the genetic algorithm is carried out in this study.

\section{Experimental Results and Analysis}

During the experiment, we randomly generated two test data as shown in Table 1; followed by the test system after several iterations, obtained to meet the requirements of the test data, as shown in table 2.

From the two table, the random test paper has 7\% gap in the test question distribution rate, and all cannot achieve full coverage. There is a gap of $30 \%$ on the difficulty coefficient, which affects the fairness of the students' assessment. We can see that the gap between the two papers on the test paper coverage and the difficulty coefficient is nearly 0 by using our approach. At the same time, we also see that using our test paper compositing algorithm, we can meet more than $90 \%$ of the fitness of the test papers according to the user setting conditions.

The implementation indicates that our proposed approach is achievable using Java program language. The Experimental results verify the effectiveness of our approach.

TABLE I. INFORMATION OF RANDOMLY COMPOSITED TEST PAPER

\begin{tabular}{|c|c|c|c|c|c|c|c|c|c|c|c|}
\hline \multirow{2}{*}{$\begin{array}{l}\text { No. } \\
1\end{array}$} & \multirow{2}{*}{$\begin{array}{l}\begin{array}{l}\text { Distribution of } \\
\text { knowledge points }\end{array} \\
0.7804878\end{array}$} & \multirow{2}{*}{$\begin{array}{l}\begin{array}{l}\text { Degree of } \\
\text { Difficulty }\end{array} \\
0.33734137\end{array}$} & \multicolumn{8}{|c|}{ The corresponding examination questions numbers } & \multirow{2}{*}{$\frac{}{77}$} \\
\hline & & & 407 & 949 & 409 & 743 & 968 & 767 & 263 & 644 & \\
\hline \multirow{13}{*}{2} & & & & 300 & 81 & 111 & 341 & 876 & 346 & 348 & 169 \\
\hline & & & & 207 & 934 & 1299 & 1645 & 1729 & 1454 & 1502 & 2002 \\
\hline & & & & 2498 & 2428 & 2515 & 2363 & 2310 & 2823 & 2718 & 2721 \\
\hline & & & & 2418 & 3435 & 3839 & 3026 & 3632 & 3294 & 3026 & 3307 \\
\hline & & & & 3641 & 3307 & 4177 & 4946 & 4879 & 4314 & 4879 & 4879 \\
\hline & & & & 4335 & 4335 & 4549 & 4314 & & & & \\
\hline & 0.85365856 & 0.64419453 & 633 & 635 & 41 & 434 & 262 & 263 & 644 & 445 & 58 \\
\hline & & & & 452 & 807 & 287 & 876 & 145 & 159 & 376 & 916 \\
\hline & & & & 921 & 727 & 1786 & 1533 & 1817 & 1679 & 1373 & 2260 \\
\hline & & & & 2351 & 2363 & 2671 & 2068 & 2198 & 2823 & 2319 & 2963 \\
\hline & & & & 2828 & 3299 & 3584 & 3029 & 3067 & 3992 & 3538 & 3083 \\
\hline & & & & 3383 & 3596 & 4365 & 4993 & 4993 & 4897 & 4335 & 4717 \\
\hline & & & & 4993 & 4440 & 4717 & 4958 & & & & \\
\hline
\end{tabular}


TABLE II. INFORMATION OF COMPOSITED TEST PAPER BY OUR METHOD

\begin{tabular}{|c|c|c|c|c|c|c|c|c|c|c|}
\hline $\begin{array}{l}\text { No. } \\
1\end{array}$ & $\begin{array}{l}\begin{array}{l}\text { Distribution of } \\
\text { knowledge points }\end{array} \\
1.0\end{array}$ & $\begin{array}{r}\begin{array}{r}\text { Degree of } \\
\text { Difficulty }\end{array} \\
0.52303314\end{array}$ & $\begin{array}{l}\text { Fitness } \\
0.90117496\end{array}$ & \multicolumn{7}{|c|}{ The corresponding examination questions numbers } \\
\hline 1 & 1.0 & & & & $\begin{array}{l}800 \\
644 \\
325 \\
77 \\
1367 \\
2407 \\
3272 \\
3987 \\
4340\end{array}$ & $\begin{array}{l}340 \\
257 \\
376 \\
727 \\
2033 \\
2823 \\
3583 \\
3307 \\
4474\end{array}$ & $\begin{array}{l}697 \\
906 \\
186 \\
1170 \\
2049 \\
2877 \\
3383 \\
4626 \\
4926\end{array}$ & $\begin{array}{l}954 \\
508 \\
80 \\
1984 \\
2746 \\
2481 \\
3258 \\
4897 \\
4717\end{array}$ & $\begin{array}{l}749 \\
100 \\
852 \\
1479 \\
2145 \\
2222 \\
3966 \\
4299 \\
4634\end{array}$ & $\begin{array}{l}645 \\
979 \\
391 \\
1405 \\
2273 \\
3240 \\
3793 \\
4065 \\
4409\end{array}$ \\
\hline 2 & 1.0 & 0.52336645 & 0.90152496 & 800 & $\begin{array}{l}340 \\
257 \\
287 \\
417 \\
2033 \\
2823 \\
3583 \\
3307 \\
4474\end{array}$ & $\begin{array}{l}697 \\
300 \\
186 \\
1170 \\
2049 \\
2877 \\
3383 \\
4626 \\
4926\end{array}$ & $\begin{array}{l}954 \\
508 \\
80 \\
1984 \\
2746 \\
2481 \\
3258 \\
4314 \\
4717\end{array}$ & $\begin{array}{l}749 \\
100 \\
852 \\
1479 \\
2145 \\
2222 \\
3966 \\
4416 \\
4634\end{array}$ & $\begin{array}{l}645 \\
979 \\
391 \\
1405 \\
2273 \\
3240 \\
3793 \\
4897 \\
4409\end{array}$ & $\begin{array}{l}644 \\
325 \\
77 \\
1367 \\
2407 \\
3272 \\
3204 \\
4712\end{array}$ \\
\hline
\end{tabular}

\section{CONCLUSION}

In this paper, online test and test based on genetic algorithm are studied and implemented in detail. Aiming at the frequent injustice of examinations, we try to realize an intelligent examination system to meet the needs of users. This uses the key technology - genetic algorithms. First initializes the test question population, numbered each test question, then selects the test question closest to the user demand through the roulette selection method, and gets the result through the crossover and mutation algorithm. If the result can't meet the user's needs, the process of cross mutation is continued, and the iteration is repeated until the user's request is met. The optimal solution is obtained. The experimental results show that, while the constraints are satisfied, the genetic algorithm can quickly form a test paper, and the test paper obtained by each user based on the constraints of its own is also different. This ensures the fairness of the examination, and provides a good study guide for the students, and greatly improves the students. Learning enthusiasm.

\section{ACKNOWLEDGMENT}

This work was partially supported by the following research grants: (1) No. BM2013123 from the Jiangsu Engineering Research Center for Networking of Elementary Education Resources and (2) No. 2016NXY46 from the Research Foundation of Nanjing Xiaozhuang University.

\section{REFERENCES}

[1] Y. Sun, "Design and implementation of online examination system based on intelligent test paper composition," Master thesis, Beijing University of Technology, 2016.

[2] X. B. Zhang, "C programming language objective question intelligent test paper system construction," Master thesis, Northwest Agriculture and Forestry University, 2014.

[3] M. Dong, J. J. Huo and X. P. Wang, "Model management system based on IRT intelligent test paper," Journal of University of Science and Technology China, 2004, 34 (5), pp. 612-617.
[4] L. Yang, "Ontology construction and its application in intelligent evaluation system,” Master thesis, University of Electronic Science and technology, 2012.

[5] D. Xiao, "Design and realization of intelligent test paper generating system,” Master thesis, University of Electronic Science and technology, 2017.

[6] H. M. Wang, "Research and implementation of test-paper combination with genetic algorithm improved by text similarity,” Modern Electronic Technology, 2016 (5), pp. 117-120.

[7] Z. M. Li, "Based on improved genetic algorithm of online test intelligent test paper generation system,” Master thesis, Zhengzhou University, 2013.

[8] W. L. Song, and L. X. Ni, "Semantic Query and Reasoning System based on ontology of Online Course," Microcomputer Applications, 2014(10), pp. 57-60.

[9] Y. P. Jin, "An intelligent exam-paper generating method based on improved genetic algorithm," Master thesis, Harbin Engineering University, 2009.

[10] C. Y. Jiao, "Research on intelligent test paper generation system based on genetic algorithm," Master thesis, Nanjing University of Science and Technology, 2011. 